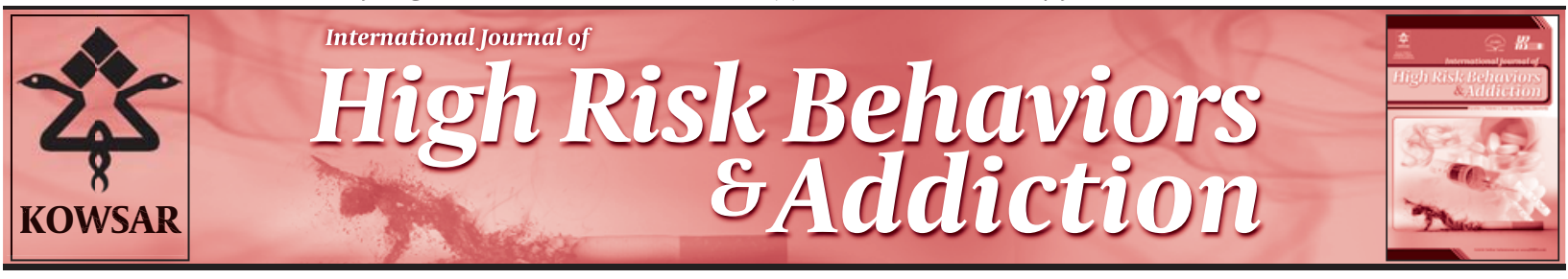

\title{
Minnesota Multiphasic Personality Inventory Score as a Predictor of Addiction Potential in Youth
}

\author{
Zahra Nikmanesh ${ }^{1^{*}}$, Mahdeie Adrom ${ }^{2}$, Nour-Mohammad Bakhshani ${ }^{3}$ \\ ${ }^{1}$ Department of Psychology, Faculty of Education and Psychology, University of Sistan and Baluchestan, Zahedan, IR Iran \\ ${ }^{2}$ Zahedan University of Medical Sciences, Zahedan, IR Iran \\ ${ }^{3}$ Department of Clinical Psychology, Zahedan University of Medical Sciences- Research Center for Children and Adolescents Health, Zahedan, IR Iran
}

\section{A R T I C L E I N F O}

Article type:

Original Article

Article history:

Received: 12 Aug 2011

Revised: 08 Sep 2011

Accepted: 10 Oct 2011

\section{Keywords:}

Personality

Addiction Potential

Adolescent

MMPI

\begin{abstract}
A B S T R A C T
Background: Drug abuse causes various societal problems, including decline in public health, increase in mortality, social and domestic traumas, loss of educational and occupational opportunities, increase in involvement with the judicial system, and development of drug abuse cycles. The tendency to use drugs is directly related to the attitudes of the individuals regarding the legality and the scale of social acceptance of drug use, the harm resulting from drug use, or the pleasant consequences of using drugs.

Objectives: The aim of the present study is to predict the psychological inclination to drug use in youths by studying their personality traits.

Patients and Methods: The research sample included students of the Medical Science University, Zahedan, Iran, with an average age of 19-24 years. Participants were selected by probability proportional cluster random sampling. The instruments were the Addiction Potential Scale (APS) and the Minnesota Multiphasic Personality Inventory (MMPI). The hypotheses were tested using the Pearson correlation method and regression analysis.

Results: Addiction potential was positively related to personality characteristics. We found that those with the highest addiction potential (47\%) exhibited the following 3 traits: characteristics of schizophrenia, psychological exhaustion, and depression.

Conclusions: There were no significant differences in the addiction potential among the students with respect to grade, field of study, age, or gender.
\end{abstract}

Copyright $\odot 2012$ Kowsar Corp. All rights reserved.

- Implication for health policy/practice/research/medical education:

The applicability of these results is for psychologists and consulters in the treatment of drug abusers. Also in the instrumental centers as schools and universities it is important to present special program according to the results this research to reduce schizophrenia, the psychological exhaustion and the depression.

- Please cite this paper as:

Nikmanesh Z, Adrom M, Bakhshani N. Minnesota Multiphasic Personality Inventory Score as a Predictor of Addiction Potential in Youth. Int J High Risk Behav Addict. 2012;1(1):22-6. DOI: 10.5812/ijhrba.4194

\section{Background}

Drug abuse is a persistent problem that has resulted in declining public health, increased mortality, social and domestic traumas, loss of educational and occupational opportunities, increased involvement with the judicial system, and development of cycles of drug abuse $(1,2)$.

\footnotetext{
* Corresponding author: Zahra Nikmanesh, Department of Psychology. Faculty of Education and Psychology, University of Sistan and Baluchestan, Zahedan, IR Iran. Tel: +98-5412430955, Fax: +98-5412416120. E-mail: zahranikmanesh@yahoo.com

DOI:10.5812/ijhrba.4194

Copyright @ 2012 Kowsar Corp. All rights reserved.
}

Addiction potential is defined by beliefs and attitudes towards drug use and perception of related consequences as either negative or positive $(3,4)$. The tendency to use drugs is directly related to the attitudes of individuals regarding the legality and the scale of social acceptance of drugs, the harm resulting from drug use, or the pleasant consequences of using drugs (5). Drug abuse is a complicated issue and has different dimensions. Therefore, any type of confrontation and intervention in this field needs to be conducted after extensive investigation. In this respect, Nielsen, Rojskjaer and Hesse, have written that prevention of drug abuse is similar to prevention 
of disease and requires identification of the causes and factors that are involved. On the basis of repeat drug use and the inability to stop using drugs observed in the cases of the majority of addicts, scholars have opined that drug abuse must have its roots in more chronic and robust structures that involve determinant forces on behavior (6). Research has shown that personality traits are among the important causalities in the tendency toward risk-taking behaviors, including cigarette smoking, alcohol and drug use, and unprotected sexual activity (7-13). Mc Crae (11) has defined personality traits as the dimensions of personal differences in the tendency toward displaying stable patterns of thought, impression, and action. Individual characteristics such as low self-esteem, depressed mood, and personal character affect a person's ideas and perceptions about drugs (14). Swendsen, Conway, Rounsaville and Merikangas (15) reported that drug abusers, in comparison with nondrug users had higher scores for alienation and negative emotions and lower scores for control, harm avoidance, and constraint. Verheul (16) has reported that the drug abusers have high rates of personality disorders, such as antisocial personality disorder, morbid personality disorder, avoidant personality disorder, and paranoia. Some researchers have found that extroverts have a greater tendency to drug and alcohol use (17-19). In other studies, drug abusers had high scores for psychosis and neurosis on evaluation with the five factors personality inventory $(20,21)$. Polimeni, Moore and Gruenert investigated the psychological profiles of addicts. Generally, the profile of this group is associated with high levels of temper disorder (Pd) and confused thoughts and emotions or schizophrenia (Sc). Psychological disorders were more common in women than in men, and women's scores for confusion, hypochondriasis, character disorder, and hysteria were significantly higher than the corresponding scores for men. Individuals with depression, character disorder, and paranoia and those aged less than 35 years had more problems (8). Craig found that the MMPI profiles of heroin addicts showed high level of psychological disorders, particularly in scales of Depression,(D) Psychopathic Deviate (Pd), and Schizophrenia (Sc) (22). This study was conducted to investigate the association between personality traits and addiction Potential in Youth. The research questions are as follows:

1) "Is there any relationship between personality traits and addiction potential among the youth?" and

2) "Which of the studied variables can better predict addiction potential among the youth?"

\section{Objectives}

The aim of the present study was to predict the psychological inclination to drug use in youths by studying their personality traits.

\section{Patients and Methods}

The method of this research is descriptive/correlation- al. Multivariate regression was used for statistical analyses. The study population consisted of students from the health, premedical, nursing, dentistry, and medical schools in the academic year 2010-2011 of the Medical Sciences University, Zahedan, Iran. The sample comprised 320 subjects ( 188 female students and 132 male students) who were selected using the proportional cluster method. The students were initially divided according to school into 5 clusters, and the size of each cluster was determined according to size of the student populations. Age range of the subjects was $19-26$ years. The subjects in each cluster completed the questionnaires in the same amount of time in their classes.

\subsection{Research Instruments}

Two questionnaires were used in this study.

1) The Minnesota Multiphasic Personality Inventory (MMPI) (containing 39 questions). The response to each one of the scale items was "yes" or "no." The clinical scales of the test are as follows: Hypochondria (Hs), Hysteria (Hy), Depression (D), Psychopathic Deviate (PD), Paranoia (Pa), Psychological Trauma (PT), Schizophrenia (Sc), and Mania (Ma). Internal coherence of this questionnaire by Cronbach Alpha coefficient was 0.78. The validity of the test was ascertained by correlating the scores of its micro scales with the SCL-90-R score. The coefficients of the subscales varied between 0.29 and 0.56 , and all the coefficients were significant at 0.001 . The reliability of the main test scales was tested using split-half method that showed coefficients between 0.70 to 0.80 . The reliability coefficients of the scales, obtained by using the retest method, ranged from 0.50 to 0.90 .

2) The Inventory of Addiction Potential Scale (APS) was used to evaluate addiction potential. Three APS subscales (23), the addiction acknowledgment scale (AAS), and the MacAndrew Alcoholism scale were used. The APS consists of 39 questions. The responses to each question was"yes" or "no." Weed (23) obtained the coefficients of reliability of the ARS in a normal sample for men (0.69) and women (0.77). In the current study, the reliability coefficient of the inventory with a sample size of 67 subjects was 0.80 .

\section{Results}

Results are presented according to the research questions posed above.

1) Is there any relationship between personality traits and addiction potential among the youth?

In order to answer this question, the Pearson correlation and analysis of regression methods were used. The results (Table 1) deomonstrated that the correlation between the addiction potential scale and all the scales of the MMPI is significant.

2) Which of the studied variables can better predict addiction potential among the youth?

The second research question was examined by regression analysis, and results are presented in Table 2, which shows that Sc was the strongest predictor and entered 


\begin{tabular}{|c|c|c|c|c|c|c|c|c|}
\hline & Hs & D & Hy & Pd & $\mathbf{P a}$ & $\mathbf{P t}$ & Sc & Ma \\
\hline APS $^{c}$ & $0.339^{b}$ & $0.316^{b}$ & $0.157^{\mathrm{a}}$ & $0.383^{b}$ & $0.394^{b}$ & $597^{b}$ & $0.638^{b}$ & $0.423^{b}$ \\
\hline $\mathrm{Hs}^{\mathrm{c}}$ & 1.000 & 0.556 & 0.577 & 0.320 & 0.436 & 0.495 & 0.431 & 0.283 \\
\hline$D^{c}$ & & 1.000 & 0.605 & 0.520 & 0.493 & 0.668 & 0.428 & 0.083 \\
\hline $\mathrm{Hy}^{c}$ & & & 1.000 & 0.487 & 0.385 & 0.407 & 0.212 & 0.029 \\
\hline $\mathrm{Pd}^{\mathrm{C}}$ & & & & 1.000 & 0.560 & 0.547 & 0.610 & 0.296 \\
\hline $\mathrm{Pa}^{\mathrm{c}}$ & & & & & 1.000 & 0.501 & 0.671 & 0.281 \\
\hline $\mathrm{Pi}^{\mathrm{c}}$ & & & & & & 1.000 & 0.674 & 0.338 \\
\hline $\mathrm{SC}^{\mathrm{c}}$ & & & & & & & 1.000 & 0.690 \\
\hline
\end{tabular}

${ }^{\mathrm{b}} P \leq 0.001$

${ }^{\mathrm{c}}$ Abbreviotions; APS, Addiction Potential Scale; D, Depression; Hs, Hypochondria; Hy, Hysteria; Pd, Psychopathic Deviate; Pa, Paranoia; Pt, Psychological Trauma; Sc, Schizophrenia; Ma, Mania

\begin{tabular}{|c|c|c|c|c|c|c|c|c|}
\hline & $\mathbf{R}^{\mathbf{d}}$ & Adjusted $\mathbf{R}^{2}$ & R Square Change & F Change & dfi $^{e}$ & df2 $^{e}$ & $P$ value & Durbin Watson \\
\hline Model 1 & $0.638^{a}$ & 0.406 & 0.407 & 218.595 & 1 & 318 & 0.000 & 1.968 \\
\hline Model 2 & $0.677^{b}$ & 0.455 & 0.051 & 29.764 & 1 & 317 & 0.000 & \\
\hline Model 3 & $0.684^{c}$ & 0.463 & 0.010 & 5.852 & 1 & 316 & 0.016 & \\
\hline
\end{tabular}

a Predictors: (Constant), Schizophrenia

b Predictors: (Constant), Schizophrenia, Psychological Trauma

c Predictors: (Constant), Schizophrenia, Psychological Trauma, Depression

${ }^{d}$ Dependent Variable: Addiction Potential Scale

e Abbreviation: df, Degree of freedom; R, Relation

\begin{tabular}{|c|c|c|c|c|c|c|c|}
\hline & $\mathbf{R}^{\mathbf{d}}$ & Adjusted $\mathbf{R}^{2}$ & R Square Change & F Change & df1 $^{d}$ & df2 $^{d}$ & Pvalue \\
\hline Model 1 & $0.642^{a}$ & 0.407 & 0.412 & 91.067 & 1 & 130 & 0.000 \\
\hline Model 2 & $0.687^{b}$ & 0.464 & 0.061 & 14.804 & 1 & 129 & 0.000 \\
\hline
\end{tabular}

a Predictors: (Constant), Schizophrenia

${ }^{b}$ Predictors: (Constant), Schizophrenia, Psychological Trauma

${ }^{\mathrm{c}}$ Unless noted otherwise, statistics are based only on cases for which gender $=$ male

d Abbreviation: df, Degree of freedom; R, Relation

\begin{tabular}{|c|c|c|c|c|c|c|c|}
\hline & $\mathbf{R}^{\mathbf{e}}$ & Adjusted $\mathrm{R}^{2}$ & R Square Change & F Change & dfi $^{e}$ & df2 ${ }^{e}$ & Pvalue \\
\hline Model 1 & $0.635^{a}$ & 0.404 & 0.404 & 125.871 & 1 & 186 & 0.000 \\
\hline Model 2 & $0.669^{b}$ & 0.448 & 0.045 & 14.935 & 1 & 185 & 0.000 \\
\hline Model 3 & $0.678^{c}$ & 0.460 & 0.012 & 4.096 & 1 & 184 & 0.044 \\
\hline
\end{tabular}

a Predictors: (Constant), Schizophrenia

b Predictors: (Constant), Schizophrenia, Psychological Trauma

${ }^{\text {c }}$ Predictors: (Constant), Schizophrenia, Psychological Trauma, Psychopathic Deviate

d Unless noted otherwise, statistics are based only on cases for which gender $=$ female

e Abbreviation: df, Degree of freedom ; R, Relation

the model first, followed by Pt and D. The first predictor accounted for $41 \%$ of the variance in the APS ( $F=218.595$, $d f=1,318, P \leq 0.001)$. The combination of the 2 predictors accounted for $45 \%$ of the variance in the APS ( $F=29.764$, $d f=1,317, P \leq 0.001)$. The combination of the 3 predictors accounted for $46 \%$ of the variance in the APS ( $F=5.852$, $d f=1,316, P \leq 0.05)$. Results of the analysis of variance (ANOVA), calculated from the 3-steps model, showed that the $\mathrm{F}$ value is significant. Results obtained for men, on comparison on the basis of gender, are shown in Table 3.

Table 3 indicates that Sc and the Pt were the predictors that entered the model for men. The 2 predictors accounted for $46 \%$ of the variance in the APS ( $F=14.804, d f$ $=1,129, P \leq 0.001$ ).
Table 4 shows that Sc, Pt, and Pd were the predictors that entered the model for women. These 3 predictors accounted for $46 \%$ of the variance in the APS $(\mathrm{F}=4.096, d f=$ $1,184, P \leq 0.05)$.

\section{Discussion}

As with the results of this research, those of other studies have shown that the MMPI profile of drug abusers is distinctive. The results of the present study also support other results that suggest that the Sc scale, associated with disordered thoughts and emotions and cognitive derangement, is related to drug abuse. Another study 
has also shown that people with high scores for this scale have numerous problems related to social skills, judgment ability, and logical thinking (24). Previous research has also found a relationship between psychological fatigue and drug abuse $(8,25,26)$. Psychological fatigue is distinguished by a high level of emotional helplessness. People with psychological fatigue feel insecure, neglected, and unwanted. Their poor social skills keep them isolated from people and social activities (24). High depression scores are related to negative emotions. Rozenfeld reported that addicts are anxious and depressed with feelings of insecurity, and they abuse drugs as a tool to obtain false euphoria (27). Low scores for depression are often associated with curiosity and extroversion. These characteristics have also been associated with drug abuse $(18,19)$. According to results of the present study, there are certain personality variables that may be important predictors of an inclination to addiction. Since personality traits are robust and rooted from childhood, interventions for prevention of drug abuse should start from childhood. The current study results also indicate that the relationship between characteristic profiles and the tendency to drug use is restrained by gender differences. Another study has emphasized that addicted women reported more problems related to depression, anxiety, and self-esteem than did addicted men, while male addicts had problems with social distortion and cognitive disorders (25). In the present study, the focus was on the variables affecting tendency to drug use in the youth, while other studies have considered the extent of drug abuse. In this research, in contrast with the other studies, no difference was found in the tendency of drug use between women and men. This result might be attributable to cultural factors. Women in Iran may have no chance to act on their tendencies because of societal constraints. However, because of the influences of tendency on behavior, the high prevalence of drug abuse in girls and boys (28) and further fading of gender limitations in developing and industrial societies (29), programs for prevention of drug abuse in women are as important as in men. Programs for women are also important because of the crucial roles of women in the family.

\section{Acknowledgments}

This paper is from a dissertation conducted at the Azad University branch of Birjand by the authors.

\section{Financial Disclosure}

No Financial disclosure .

\section{Funding/Support}

No Supported.

\section{References}

1. Ellickson PL, Tucker JS, Klein DJ. High-risk behaviors associated with early smoking: results from a 5-year follow-up. J Adolesc Health. 2001;28(6):465-73.
2. Logan T, Walker R, Cole J, Leukefeld C. Victimization and substance abuse among women: Contributing factors, interventions, and implications. Rev Gen Psychol. 2002;6(4):325.

3. Erickson PG. Illicit drug use, peer attitudes, and perceptions of harmful effects among convicted cannabis offenders. Int J Addict. 1982;17(1):141-54.

4. Brook JS, Lukoff IF, Whiteman M. Peer, family, and personality domains as related to adolescents drug behavior. Psychol Rep. 1977;41(3 pt. 2):1095-102.

5. Sarvela PD, McClendon E. Indicators of rural youth drug use. $J$ Youth Adolesc. 1988;17(4):335-47.

6. Walton KE, Roberts BW. On the relationship between substance use and personality traits: Abstainers are not maladjusted.J Res Pers. 2004;38(6):515-35.

7. Stefánsson R, Hesse M. Personality disorders in substance abusers: A comparison of patients treated in a prison unit and patients treated in inpatient treatment. Int J Ment Health Addict. 2008;6(3):402-6.

8. Polimeni AM, Moore SM, Gruenert S. MMPI-2 profiles of clients with substance dependencies accessing a therapeutic community treatment facility. Eur J Appl Psychol. 2010;6(1).

9. Nielsen P, Rojskjaer S, Hesse M. Personality-guided treatment for alcohol dependence: a quasi-randomized experiment. Am J Addict. 2007;16(5):357-64.

10. Kopstein AN, Crum RM, Celentano DD, Martin SS. Sensation seeking needs among 8th and 11th graders: characteristics associated with cigarette and marijuana use. Drug Alcohol Depend. 2001;62(3):195-203.

11. McCrae RR, Costa PT, Jr. Validation of the five-factor model of personality across instruments and observers.J Pers Soc Psychol. 1987;52(1):81-90.

12. Kornor H, Nordvik H. Five-factor model personality traits in opioid dependence. BMC Psychiatry. 2007;7:37.

13. Ball SA, Carroll KM, Canning-Ball M, Rounsaville BJ. Reasons for dropout from drug abuse treatment: symptoms, personality, and motivation. Addict Behav. 2006;31(2):320-30.

14. Sussman S, Dent CW, Leu L. The one-year prospective prediction of substance abuse and dependence among high-risk adolescents. J Subst Abuse. 2000;12(4):373-86.

15. Swendsen JD, Conway KP, Rounsaville BJ, Merikangas KR. Are personality traits familial risk factors for substance use disorders? Results of a controlled family study. Am J Psychiatry. 2002;159(10):1760-6.

16. Verheul R. Co-morbidity of personality disorders in individuals with substance use disorders. Eur Psychiatry. 2001;16(5):274-82.

17. Kwapil TR, Miller MB, Zinser MC, Chapman LJ, Chapman J, Eckblad M. A longitudinal study of high scorers on the hypomanic personality scale. J Abnorm Psychol. 2000;109(2):222-6.

18. Meyer TD, Hautzinger M. Screening for bipolar disorders using the Hypomanic Personality Scale. J Affect Disord. 2003;75(2):14954 .

19. Meyer TD, Hofmann BU. Assessing the dysregulation of the Behavioral Activation System: the Hypomanic Personality Scale and the BIS-BAS scales. J Pers Assess. 2005;85(3):318-24.

20. Sher KJ, Bartholow BD, Wood MD. Personality and substance use disorders: a prospective study. J Consult Clin Psychol. 2000;68(5):818-29.

21. Terracciano A, Costa PT, Jr. Smoking and the Five-Factor Model of personality. Addiction. 2004;99(4):472-81.

22. Craig RJ. Personality characteristics of heroin addicts: review of empirical research 1976-1979. Int J Addict. 1982;17(2):227-48.

23. Weed NC, Butcher JN, McKenna T, Ben-Porath YS. New measures for assessing alcohol and drug abuse with the MMPI-2: The APS and AAS. J Pers Assess. 1992;58(2):389-404.

24. Greene RL. The MMPI-2: An interpretive manual. Allyn \& Bacon; 2000.

25. De Leon G. Psychopathology and substance abuse: what is being learned from research in therapeutic communities. J Psychoactive Drugs. 1989;21(2):177-88.

26. Kidner CL, Gatchel RJ, Mayer TG. MMPI disability profile is associated with degree of opioid use in chronic work-related musculoskeletal disorders. Clin J Pain. 2010;26(1):9-15.

27. Ghafuri F, Hovanlou F, Asghari A, Arshadi R. Relationship Between Kyphosis And Depression And Anxiety In Athlete And 
Non-Athlete Male Students In Selected University Of Tehran Res Sports Sci. 2006;12(107):12.

28. Fisher.B.S, Cullen FT, Turner MG, ,. Being pursued: Stalking victimization in a national study of college women. Criminol Public
Policy. 2002;1(2):257-308

29. Moracco KE, Runyan CW, Bowling JM, Earp JA. Women's experiences with violence: a national study. Womens Health Issues. 2007;17(1):3-12. 